\title{
PARP inhibitor re-sensitizes Adriamycin resistant leukemia cells through DNA damage and apoptosis
}

\author{
JIE WU $^{1}$, SHENG XIAO ${ }^{1}$, MIAOMIAO YUAN ${ }^{1}$, QIANYUAN LI ${ }^{1}$, GUANGFEN XIAO $^{1}$, \\ WEI WU ${ }^{1}$, YUEXIAN OUYANG ${ }^{2}$, LIHUA HUANG ${ }^{2}$ and CHENJIAO YAO ${ }^{1}$ \\ ${ }^{1}$ Department of Hematology; ${ }^{2}$ Center for Medical Experiments, \\ The Third Xiangya Hospital of Central South University, Changsha, Hunan 410013, P.R. China
}

Received March 7, 2018; Accepted September 10, 2018

DOI: $10.3892 / \mathrm{mmr} .2018 .9628$

\begin{abstract}
Resistance to Adriamycin (ADR) is an increasing problem in the treatment of leukemia and the development of novel therapeutic strategies is becoming increasingly important. Olaparib is a poly (adenosine diphosphate-ribose) polymerase (PARP) 1 inhibitor, which has promising antitumor activity in patients with metastatic breast cancer and germline BRCA mutations. Previously published studies have indicated that Olaparib is able to overcome drug resistance in cancer; however, its underlying mechanism of action is yet to be elucidated. The aim of the present study was to explore the mechanism underlying re-sensitization. Annexin V-propidium iodide staining indicated that the percentage of apoptotic ADR resistant cells was markedly increased and the cell cycle was blocked at the G2/M-phase following treatment with ADR combined with Olaparib, when compared with the control group. The alkaline comet assay demonstrated that ADR combined with Olaparib significantly upregulated the induction of the DNA damage response in ADR-resistant cells. Western blot analysis revealed that the protein expression of $\gamma$-H2A histone family member X, cleaved PARP, caspase 3 and cleaved caspase 3 was markedly enhanced, while the cell cycle-associated protein cyclin B1 was downregulated in K562/ADR cells following treatment with a combination of ADR and Olaparib. Similar synergistic cytotoxicity was observed in blood mononuclear cells, which were isolated from patients with chemotherapy-resistant leukemia. As Olaparib is available for clinical use, the results of the present study provide a rationale for the development of Olaparib combinational therapies for cases of ADR resistant leukemia.
\end{abstract}

Correspondence to: Professor Chenjiao Yao, Department of Hematology, The Third Xiangya Hospital of Central South University, 138 Tongzipo Road, Changsha, Hunan 410013, P.R. China E-mail: yaochenjiao10888@163.com

Key words: Olaparib, drug resistance, leukemia, apoptosis, Adriamycin

\section{Introduction}

Leukemia is an aggressive hematologic malignancy, with a poor prognosis. The poor clinical outcomes that are observed in patients with leukemia are associated with the high proportion of patients who develop resistance to Adriamycin (ADR) therapy $(1,2)$. The development of ADR resistance can be attributed to a number of different factors including, increased drug efflux, changes in the expression of chemoresistance associated genes and the enhancement of DNA damage repair inside cells, as well as the inhibition of apoptosis $(3,4)$. Among these, the reversal of chemoresistance by attenuating DNA damage repair and inducing apoptosis have recently attracted widespread attention amongst researchers in this area of medicine.

Poly (adenosine diphosphate-ribose) polymerase (PARP) 1 inhibitors are used as a monotherapy to induce cell death in tumors with BRCA mutations (5), or those with a BRCA-like phenotype (also known as BRCAness) (6). PARP inhibitors have a cytotoxic effect via several mechanisms, including inhibition of PARP1/2, auto-PARylation, blocking PARP1/2 release from substrate DNA, or hypersensitivity to trapped PARP1-DNA complexes (7). Olaparib (Lynparza; AstraZeneca, Cambridge, UK) is an oral, first-in-class PARP inhibitor, which is approved by the US Food and Drug Administration (FDA) for the treatment of patients with advanced germline BRCA-mutated ovarian cancer (8). Olaparib has antitumor activity in sporadic cases of metastatic- and castration-resistant prostate cancer with DNA-repair defects, as determined by a phase II trial of Olaparib in patients with advanced metastatic resistant prostate cancer (9). The FDA has stated that it plans to approve Olaparib for use in castration-resistant prostate cancers, beyond germline BRCA mutations (10).

Previously published studies by the authors have revealed that the Fanconi anemia (FA)/BRCA signaling pathway is involved in the acquired ADR resistance of leukemia cells (11), and that extensive crosstalk exists within the DNA repair pathway (12). PARP1 inhibitors can strengthen DNA damage when combined with traditional chemotherapy drugs. Recent studies have suggested that PARP inhibitors are able to reverse drug resistance by targeting the FA/BRCA signaling pathway (13), and that disruption of FA- or other HR-associated genes also sensitizes cells to PARP inhibitors $(14,15)$. This 
provides strong rationale for the development of PARP inhibitors as a cancer therapy. PARP1 inhibitors also appear to exhibit a degree of protection against ADR-induced cardiotoxicity (16). By combining PARP1 inhibitors with traditional chemotherapy, it may be possible to lower the dosage and reduce the toxic side effects commonly associated with many chemotherapeutic agents. Therefore, the aim of the present study was to explore whether PARP1 inhibitors enhance sensitivity to ADR in ADR-resistant leukemia cells. Furthermore, the synergistic effects of ADR on apoptosis were also investigated.

\section{Materials and methods}

Cell culture patient samples and drugs. Bone marrow samples of three patients with chemoresistant leukemia from The Third Xiangya Hospital of Central South University (Hunan, China) were collected once written informed consent was obtained (Table I). Primary refractory or resistant disease was defined as not achieving complete remission (CR; i.e., a remaining blast count of $\geq 5 \%$ following 1 to 2 cycles of intense induction therapy) (17) The characteristics of patients with leukemia are presented in Table I. The present study was approved by the Central South University, and the approved protocol was in accordance with the Declaration of Helsinki. Mononuclear cells were isolated using a lymphocyte separation medium (Mediatech, Manassas, VA, USA) (18).

The K562/ADR and K562 human leukemic cell lines were a generous gift from the Cell Center of Xiangya School of Medicine (Changsha, Hunan, China). K562 cell lines were grown in RPMI-1640 medium supplemented with $10 \%$ heat-inactivated fetal bovine serum (both Gibco; Thermo Fisher Scientific, Inc., Waltham, MA, USA). K562/ADR cells were grown in culture medium containing $1 \mu \mathrm{M}$ ADR (Nanjing KeyGen Biotech, Co., Ltd., Nanjing, China) to maintain drug resistance. Cells were grown at $37^{\circ} \mathrm{C}$ in an atmosphere of $95 \% \mathrm{O}_{2}$ and $5 \% \mathrm{CO}_{2}$.

Drug treatment and survival assay. The stock solution of Olaparib (Selleck Chemicals, Houston, TX, USA) was prepared by dissolving $10 \mathrm{mg}$ of the drug in $50 \mu \mathrm{l}$ of dimethyl sulfoxide (Amresco, LLC, Solon, OH, USA). Then it was diluted with RPMI to a concentration of $5 \mu \mathrm{mol}$. The aliquots were stored at $-80^{\circ} \mathrm{C}$. For each experiment a new aliquot was thawed and used.

Cell viability was measured using Cell Counting kit- 8 (CCK-8; Dojindo Molecular Technologies, Inc., Kumamoto, Japan) according to the manufacturer's instructions. Cells were seeded at $1 \times 10^{5}$ cells $/ \mathrm{ml}$ in duplicate for each time point ( $24 \mathrm{~h}, 48 \mathrm{~h}$ and $72 \mathrm{~h}$ ) in a 96-well culture plate. K562 and K562/ADR cells were exposed to $0,2,4,8,16$ and $32 \mu \mathrm{mol} / 1$ $\mathrm{ADR}$ at $37^{\circ} \mathrm{C}$ for 24,48 and $72 \mathrm{~h}$ respectively. K562/ADR cells at $1 \times 10^{5}$ cells $/ \mathrm{ml}$ in a 96 -well culture plate were exposed to $0,1.25,2.5,5$ and $10 \mu \mathrm{mol} / 1$ Olaparib at $37^{\circ} \mathrm{C}$ for $72 \mathrm{~h}$. Then $10 \mu \mathrm{lCCK}-8$ solution was added to each well and plates were incubated at $37^{\circ} \mathrm{C}$ for $4 \mathrm{~h}$. The absorbance at $570 \mathrm{~nm}$ was then measured using a microplate reader (BioTek Instruments, Inc., Winooski, VT, USA). All experiments were performed in triplicate, and three independent experiments were conducted.
RNA extraction and reverse transcription-quantitative polymerase chain reaction $(R T-q P C R)$. A Total RNA Extractor (Omega Bio-Tek, Inc., Norcross, GA, USA) and RT-PCR kit (Toyobo Life Science, Osaka, Japan) were used for cDNA synthesis $\left(25^{\circ} \mathrm{C}\right.$ for $10 \mathrm{~min}$ and $42^{\circ} \mathrm{C}$ for $50 \mathrm{~min}$, followed by $70^{\circ} \mathrm{C}$ for $15 \mathrm{~min}$ ). SYBR-Green reagents (Toyobo Life Science, Osaka, Japan) were used to determine PARP1 and $\gamma$-H2A histone family member X (H2AX) expression. The thermocycling conditions consisted of the following: Initial denaturation for $2 \mathrm{~min} 30 \mathrm{sec}$ at $95^{\circ} \mathrm{C}$, followed by 40 cycles of denaturation for $30 \mathrm{sec}$ at $95^{\circ} \mathrm{C}$, annealing for $30 \mathrm{sec}$ at $58^{\circ} \mathrm{C}$ and extension for $30 \mathrm{sec}$ at $72^{\circ} \mathrm{C}$, then a final extension at $72^{\circ} \mathrm{C}$ for $10 \mathrm{~min}$. The gene expression level was normalized using the endogenous control gene glyceraldehyde 3-phosphate dehydrogenase (GAPDH). RT-qPCR reactions were performed using a Master Cycler Ep Realplex (Eppendorf, Hamburg, Germany). Relative expression was evaluated using the $2^{-\Delta \Delta \mathrm{Cq}}$ method (17). All PCR assays were performed three times. The primers for the individual genes were as follows: PARP1 forward, 5'-TACCAT CCAGGCTGCTTTGTCA-3' and reverse, 5'-CTTCGCCAC TTCATCCACTCCA-3'; $\gamma$-H2AX forward, 5'-GGCCTCCAG TTCCCAGTG-3' and reverse, 5'-TCAGCGGTGAGGTAC TCCAG-3'; and GAPDH forward, 5'-GACTCATGACCACAG TCCATGC-3' and reverse, 5'-AGAGGCAGGGATGATGTT CTG-3'.

Western blot analysis. Cells $\left(5 \times 10^{5} / \mathrm{ml}\right)$ were exposed to $2 \mu \mathrm{M}$ ADR, $5 \mu \mathrm{M}$ Olaparib, or a combination of the two drugs at $37^{\circ} \mathrm{C}$ for 3 days. Subsequently, they were collected by centrifugation $\left(30,000 \mathrm{x}\right.$ g for $5 \mathrm{~min}$ at $\left.4^{\circ} \mathrm{C}\right)$, washed with cold PBS, and finally lysed with a cell lysis buffer (Cell Signaling Technology, Inc., Danvers, MA, USA). The protein concentrations were determined using a BCA Protein Assay kit (Thermo Fisher Scientific, Inc.). Equal amounts of protein lysates were then mixed with SDS-PAGE protein loading buffer, boiled for $5 \mathrm{~min}$, and then run on $10 \%$ SDS-PAGE. Proteins were then transferred onto polyvinylidene fluoride membranes, which were blocked with 5\% skimmed milk powder in Tris-buffered saline with $0.1 \%$ Tween 20 (Beijing Solarbio Science \& Technology Co., Ltd.) for $2 \mathrm{~h}$ at $4^{\circ} \mathrm{C}$. Membranes were incubated with the following primary antibodies at $4^{\circ} \mathrm{C}$ overnight: PARP1 (1:1,000; cat. no. YT595; Immunoway Biotechnology Company, Plano, TX, USA); $\gamma$-H2AX (1:1,000; cat. no.pSer139; Novus Biologicals, LLC, Littleton, CO, USA); caspase 3 (1:1,000; cat. no. ab32351), cleaved-PARP (1:1,000; cat. no. ab4830; both Abcam, Cambridge, UK); cyclinB1 (1:1,000; cat. no. 4138); cleaved-caspase 3 (1:2,000; cat. no. 1177; both CST, Biological Reagents Co., Ltd., Shanghai, China); and $\beta$-actin (1:3,000; cat. no. 20536-1-AP; ProteinTech Group, Inc., Chicago, IL, USA). The next morning, the membranes were incubated with horseradish peroxidase (HRP)-conjugated goat anti-mouse or rabbit secondary antibody (cat. no. sc-2031; 1:10,000; Santa Cruz Biotechnology, Inc., Dallas, TX, USA) for $2 \mathrm{~h}$ at room temperature. Following washing with PBS (Gibco; Thermo Fisher Scientific, Inc.) at room temperature for 5 minute, bands were captured with a Gel imaging system (Bio-Rad Laboratories, Inc., Hercules, CA, USA). The relative expression of target proteins was calculated with ImageJ version 2x (National Institutes of Health, Bethesda, MD, USA) and normalized to $\beta$-actin. 
Table I. Characteristics of patients with leukemia.

\begin{tabular}{llllrr}
\hline Patient & Age (years) & Sex & FAB type & Blast count $(\%)$ & IC ${ }_{50}(\mu$ mol $)$ \\
\hline 1 & 21 & Female & AML-M1 & 10 & 21.85 \\
2 & 36 & Male & AML-M2b & 38.19 \\
3 & 52 & Male & AML-M5 & 15 & 14.17
\end{tabular}

FAB, French-American-British; AML, acute myeloid leukaemia.

Cell counting assay. For survival assays, stimulated K562/ADR cells were collected, centrifuged (10,000 x g for 5 min at $4^{\circ} \mathrm{C}$ ), suspended in a fresh complete medium (time 0 on the graphics), and seeded at $5 \times 10^{5}$ cells $/ \mathrm{ml}$ in each well of 6-well culture plates. K562/ADR cells were divided into four treatment groups: i) a control group (medium only); ii) $2 \mu \mathrm{M}$ ADR; iii) $5 \mu \mathrm{M}$ Olaparib; iv) and a combination group of the two drugs at $37^{\circ} \mathrm{C}$ for 3 days. Cells were counted via a trypan blue dye exclusion assay in quadruplicate, once the cells were dispersed, $10 \mu \mathrm{l}$ of cell suspension was transferred to a micro centrifuge tube, $10 \mu 1$ of trypan blue (Beijing Solarbio Science \& Technology Co., Ltd.; C0040) was then added and mixed gently with a pipette; $10 \mu \mathrm{l}$ of cell/trypan blue suspension was then loaded into a cell counting chamber and placed under an inverted microscope (Nikon Corporation, Tokyo, Japan) for counting. The assays were performed 3 days post-drug exposure. All of the experiments were performed three times each, and all three experiments were conducted independently.

Cell apoptosis assay. Cell apoptosis was analyzed using an Annexin V/propidium iodide (PI) kit (Nanjing KeyGen Biotech, Co., Ltd.) according to the manufacturer's protocol. Cells were collected and analyzed on a FACS Canto II (BD Biosciences, San Jose, CA, USA) flow cytometer. To determine cell cycle distribution, $8 \times 10^{4}$ K562/ADR cells were seeded in $6 \mathrm{~cm}$ dishes for a total of 3 days following lentiviral infection. Following the 3 -day culture, the cells were washed twice with ice-cold PBS and were re-suspended in a PBS (ZSGB-BIO; OriGene Technologies, Inc., Beijing, China) containing $50 \mu \mathrm{g} / \mathrm{ml}$ RNaseA (Nanjing KeyGen Biotech, Co., Ltd.) and $50 \mu \mathrm{g} / \mathrm{ml}$ PI (Nanjing KeyGen Biotech, Co., Ltd.). Cells were incubated at $37^{\circ} \mathrm{C}$ in the dark for $1 \mathrm{~h}$. The percentage of cells in each phase of the cell cycle was measured using FACScan (BD Biosciences) and subsequently the results were analyzed using ModFit software, version 3.2 (Verity Software House, Inc., Topsham, ME, USA).

Cell cycle analysis. Following a total of 3 days, the treatment groups were subjected to cell cycle analysis. Following centrifugation at $300 \mathrm{x} \mathrm{g}$ for $5 \mathrm{~min}$ at room temperature, cells $\left(1 \times 10^{6}\right)$ were fixed with $70 \%$ ethanol on ice for $2 \mathrm{~h}$, followed by centrifugation for $5 \mathrm{~min}$ at $300 \mathrm{x} \mathrm{g}$ at $4^{\circ} \mathrm{C}$. Subsequently, $0.05 \mathrm{mg} / \mathrm{ml}$ PI (Nanjing KeyGen Biotech, Co., Ltd.) and $0.1 \mathrm{mg} / \mathrm{ml}$ RNAse A (Nanjing KeyGen Biotech, Co., Ltd.) were added to the samples at room temperature in the dark for $30 \mathrm{~min}$. Cells were examined using a BD FACSCalibur flow cytometer (BD Biosciences) and Cell Quest software version 3.3 (BD Biosciences). The experiments were repeated three times.

Alkaline comet assay. The alkaline comet assay was used to detect ADR-induced DNA damage in K562/ADR cells. A total of $1 \times 10^{5}$ cells were treated with either $2 \mu \mathrm{M}$ ADR, $5 \mu \mathrm{M}$ Olaparib, or a combination of the two drugs for at $37^{\circ} \mathrm{C}$ for 3 days. Then, cells were washed in PBS and resuspended in ice-cold PBS. A total of $\sim 10 \mu 1$ of the re-suspended cells were mixed with $65 \mu \mathrm{l}$ of a low melting point agarose at $4^{\circ} \mathrm{C}$. The slides were placed at $4^{\circ} \mathrm{C}$ in the dark until gelling occurred, at which point they were immersed in a pre-chilled lysis buffer at $4^{\circ} \mathrm{C}$. Following a $1 \mathrm{~h}$ incubation period, the buffer was aspirated and replaced with pre-chilled alkaline solution for 90-120 min at $4^{\circ} \mathrm{C}$. Following lysis and DNA double strand unwinding into a single strand, the slides were placed in a horizontal electrophoresis tank filled with freshly prepared alkaline electrophoresis buffer. Electrophoresis was run for $30 \mathrm{~min}$ at $25 \mathrm{~V}$ and $300 \mathrm{~mA}$. Following this, the slides were transferred to a neutralizing buffer for $10 \mathrm{~min}$, and then aspirated. This was repeated three times. Thereafter, the slides were allowed to air dry, and $50 \mu \mathrm{l} /$ well of $5 \mathrm{mg} / \mathrm{ml}$ PI was added to each slide for $5 \mathrm{~min}$ in the dark at room temperature for DNA staining. DNA migration was observed using a fluorescence microscope (Olympus Corporation, Tokyo, Japan). For each sample, 200 cells were selected at random and were analyzed using CASP software version 1.2.2 (Comet Assay Software Project, Beijing, China).

Exposure of mononuclear cells from patients with chemoresistant leukemia, to Olaparib combined with ADR. To determine the potential clinical significance of the cell line studies, the present study isolated mononuclear cells from patients with chemoresistant leukemia, Each sample cells were divided into two parts; one part at $1 \times 10^{5}$ cells $/ \mathrm{ml}$ were seeded in duplicate in a 96-well culture plate. The cells were exposed to $0,2,4,8,16$ and $32 \mu \mathrm{mol} / 1 \mathrm{ADR}$ at $37^{\circ} \mathrm{C}$ for 3 days. Then $10 \mu \mathrm{lCCK}-8$ solution was added to each well and plates were incubated at $37^{\circ} \mathrm{C}$ for $4 \mathrm{~h}$. The absorbance at $570 \mathrm{~nm}$ was then measured using a microplate reader (BioTek Instruments, Inc., Winooski, VT, USA). The other part of the sample was exposed to $2 \mu \mathrm{M}$ ADR, $5 \mu \mathrm{M}$ Olaparib, or a combination of the two drugs at $37^{\circ} \mathrm{C}$ for 3 days. Subsequently, the cells were collected by centrifugation $\left(30,000 \times \mathrm{g}\right.$ for $5 \mathrm{~min}$ at $\left.4^{\circ} \mathrm{C}\right)$, washed with cold PBS, and finally lysed with a cell lysis buffer (Cell Signaling Technology, Inc.). Western blotting, as above was then performed to analyze the levels of the selected proteins. 

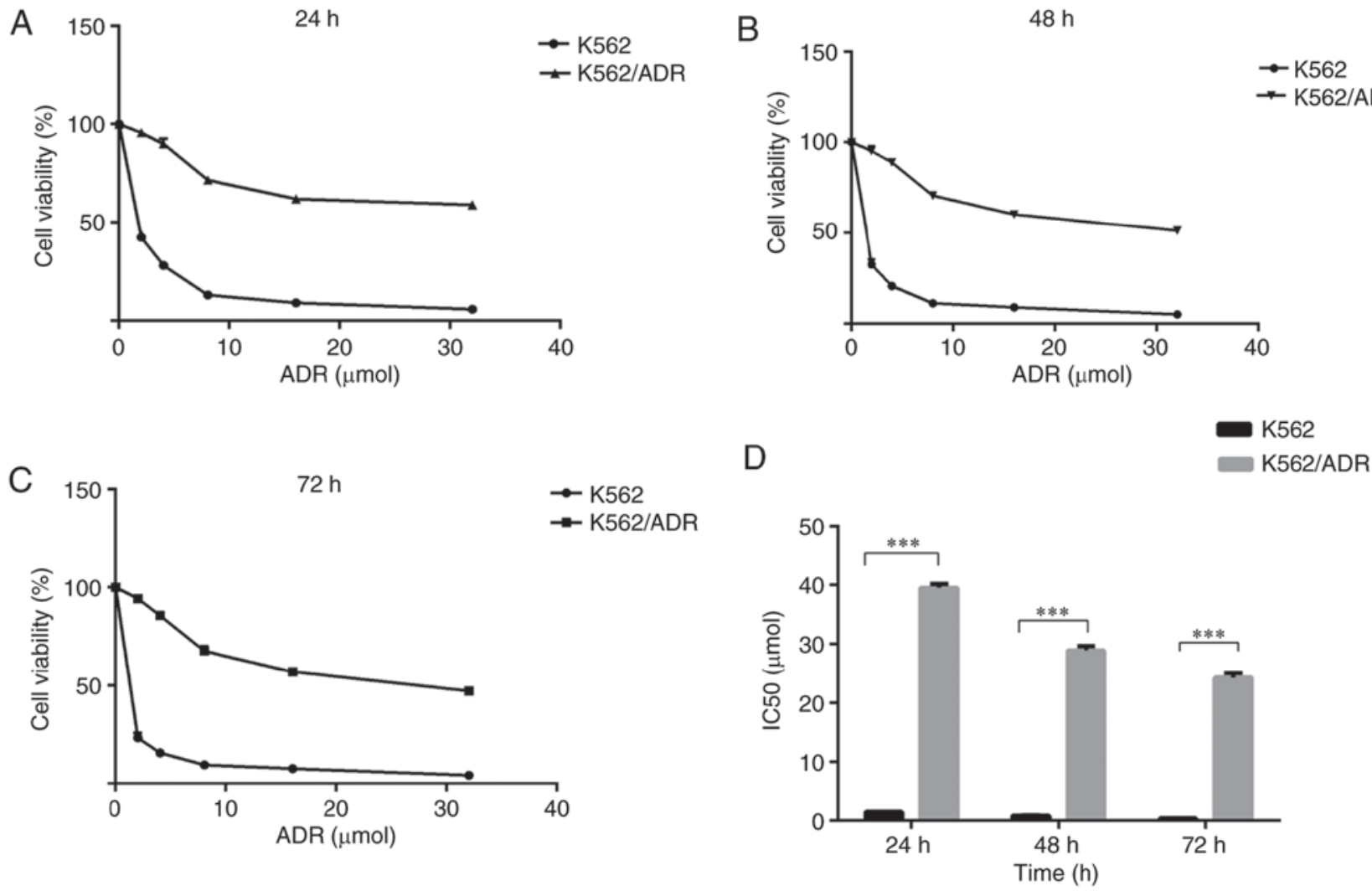

Figure 1. ADR causes greater inhibition of proliferation in K562 cells when compared with K562/ADR cells. K562 and K562/ADR cells were exposed to 0, 2 4, 8,16 and $32 \mu \mathrm{mol} / 1$ ADR for (A) 24, (B) 48 and (C) $72 \mathrm{~h}$, and Cell Counting kit-8 assays were subsequently performed to detect the cell viability. (D) IC 50 values of ADR for K562 and K562/ADR cells. Results are presented as the mean \pm standard deviation of three separate experiments. ${ }^{* * *} \mathrm{P}<0.001$, as indicated. $\mathrm{ADR}$, Adriamycin; $\mathrm{IC}_{50}$, half-maximal inhibitory concentration.

Statistical analysis. Statistical analyses was performed using GraphPad Prism 6.02 version software (GraphPad Software, Inc., La Jolla, CA, USA). The data were expressed as the mean \pm standard deviation (SD), and statistical comparisons were made using the two-tailed Student's t-test and one-way analysis of variance followed by Fisher's Least Significant Difference for multiple comparisons. All of the experiments were repeated at least three times as independent experiments in order to be effective. $\mathrm{P}<0.05$ was considered to indicate a statistically significant difference.

\section{Results}

$A D R$ inhibits the proliferation of $K 562$ cells more than K562/ADR cells. To investigate the sensitivity of K562/ADR and K562 cells to chemotherapeutic drugs, the two cell lines were treated with a gradually increasing concentration of ADR at different times as indicated. The CCK- 8 assay revealed that ADR inhibited the growth of K562/ADR and K562 cells to varying degrees. ADR-induced cytotoxicity was dose- and time-dependent in the two cell lines (Fig. 1). The half-maximal inhibitory concentration $\left(\mathrm{IC}_{50}\right)$ values of ADR were calculated for $\mathrm{K} 562$ and K62/ADR cells. The $\mathrm{IC}_{50}$ values of $\mathrm{ADR}$ for $\mathrm{K} 562$ cells were $1.50 \pm 0.03,0.82 \pm 0.09$ and $0.40 \pm 0.05 \mu \mathrm{mol} / 1$ at 24,48 and $72 \mathrm{~h}$, respectively. In addition, the corresponding values for the K562/ADR cells were 39.51 \pm 0.64 , 28.93 \pm 0.74 and $24.31 \pm 0.78 \mu \mathrm{mol} / 1$, respectively (Fig. 1D). The degree of ADR-resistance in K562/ADR cells was 26.34-60.70 fold greater when compared with K562 cells, which suggests that K562/ADR cells may have greater potential for resistance to ADR compared with K562 cells.

Olaparib enhances apoptosis and arrests cell cycle progression in K562/ADR cells. In the present study, $2 \mu \mathrm{M}$ ADR and $5 \mu \mathrm{M}$ Olaparib were selected for use in the experiments for the following reasons: i) ADR at $2 \mu \mathrm{M}$ consistently enhanced toxicity in the K562 cell line, but not in the K562/ADR cell line (Fig. 1); and ii) Olaparib alone did not exhibit a cytotoxic effect on the viability of K562/ADR cells at doses up to $5 \mu \mathrm{M}$ as determined by CCK-8 assays (Fig. 2A). The proliferation capability of K562/ADR cells was inhibited and cell growth was slower in the group treated with ADR+Olaparib for 3 days (Fig. 2B), which was significantly different compared with the other control group. This indicated that the cells treated with ADR+Olaparib had reduced proliferation rates when compared with cells treated with Olaparib alone, or in the untreated control cell group $(\mathrm{P}<0.01$; Fig. $2 \mathrm{~B})$.

The percentage of apoptotic cells was measured by flow cytometry using Annexin V/PI staining. Notably, there was a significantly increased population of apoptotic cells in the combined treatment group $(11.23 \pm 0.64 \%)$ when compared with the untreated control group $(3.72 \pm 0.24 \%$; $\mathrm{P}<0.001)$, the ADR group $(4.30 \pm 0.31 \% ; \mathrm{P}<0.001)$ and the Olaparib group $(4.42 \pm 0.66 \% ; \mathrm{P}<0.001)$. Therefore, combined treatment with Olaparib significantly improved the apoptotic percentage of K562/ADR cells (Fig. 2C and D). 
A
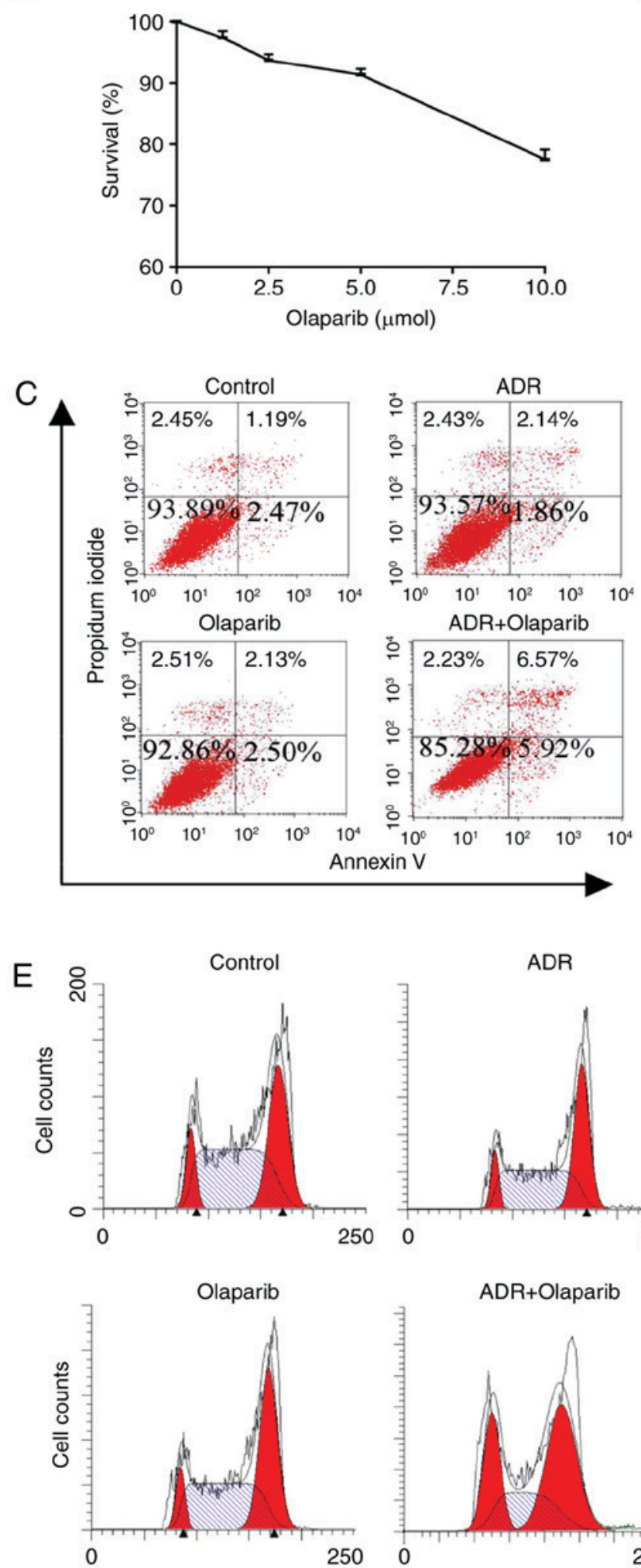

B

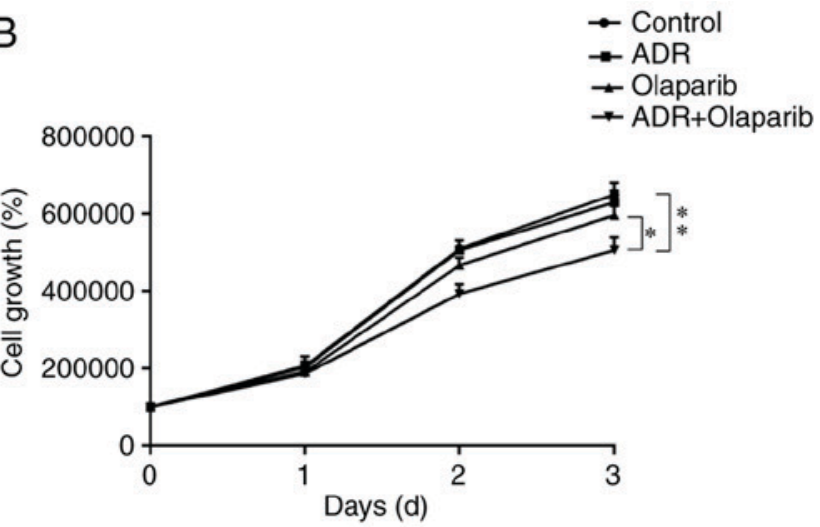

D

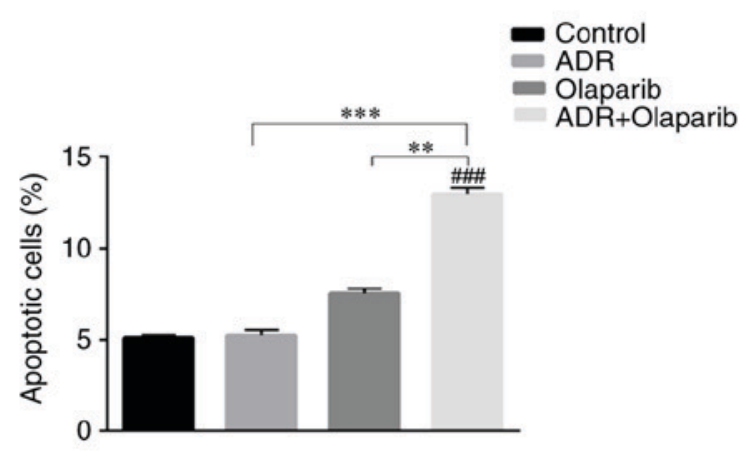

$\mathrm{F}$

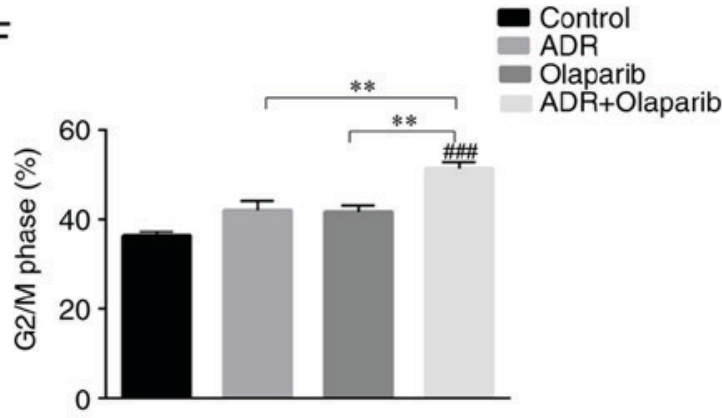

Figure 2. Effect of ADR and Olaparib on the cell cycle and apoptosis. (A) K562/ADR cells were exposed to 0, 1.25, 2.5, 5, and $10 \mu \mathrm{mol} / 1$ ADR for 3 days, and cell counting assays were subsequently performed to detect cell viability. (B) The survival of K562/ADR cells treated with ADR + Olaparib for 3 days. (C) Apoptosis was analyzed by flow cytometry. Panels of a representative experiment are presented. (D) The percentage of Annexin V positive cells at the indicated times in association with the total number of cells. (E) Cell cycle progression of K562/ADR cells treated with ADR+Olaparib for 3 days. (F) The percentage of G2/M cycle phase cells. (G) The representative western blotting image of Cyclin B1 of K562/ADR cells treated with ADR+Olaparib for 3 days. Data are presented as the mean \pm standard deviation. ${ }^{*} \mathrm{P}<0.05,{ }^{* *} \mathrm{P}<0.01$ and ${ }^{* * *} \mathrm{P}<0.001$, as indicated; ${ }^{\# \# "} \mathrm{P}<0.001$ vs. Control. ADR, Adriamycin.

To investigate whether cell cycle arrest contributed to growth inhibition, flow cytometry analysis was performed.
Treatment with ADR+Olaparib significantly increased the percentage of K562/ADR cells in the G2/M phase. The 
A

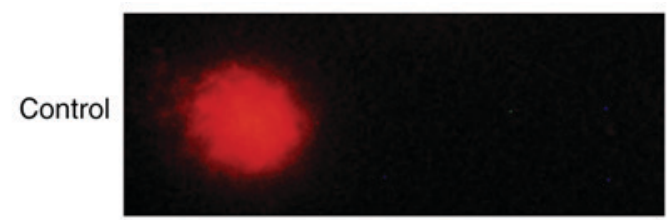

$\mathrm{ADR}$

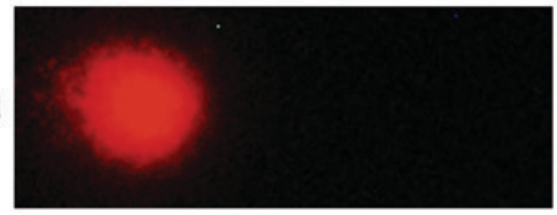

ADR+Olaparib

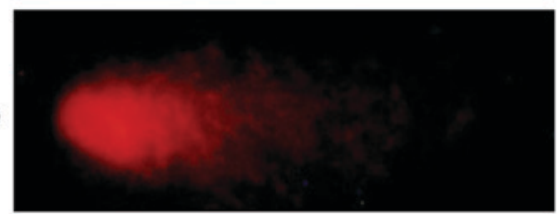

Olaparib

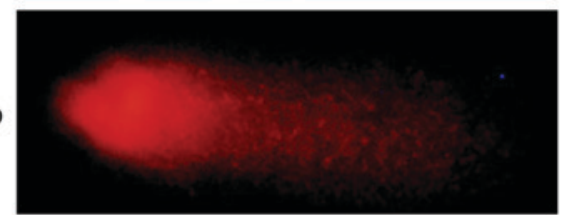

B

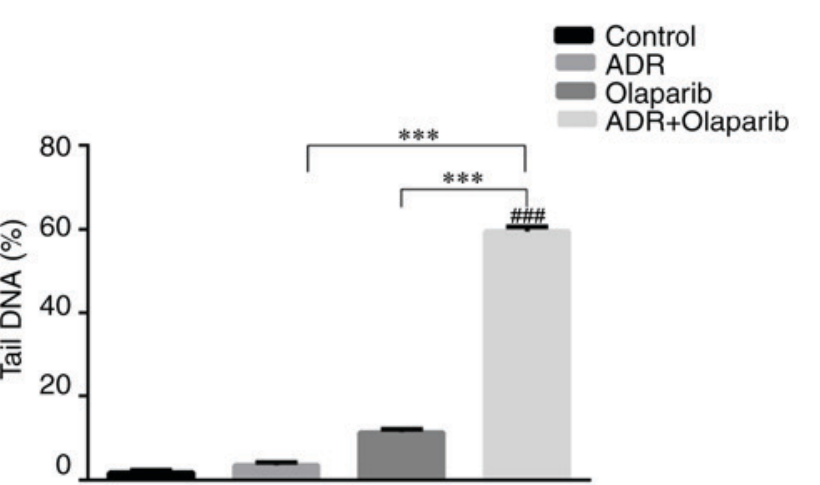

C
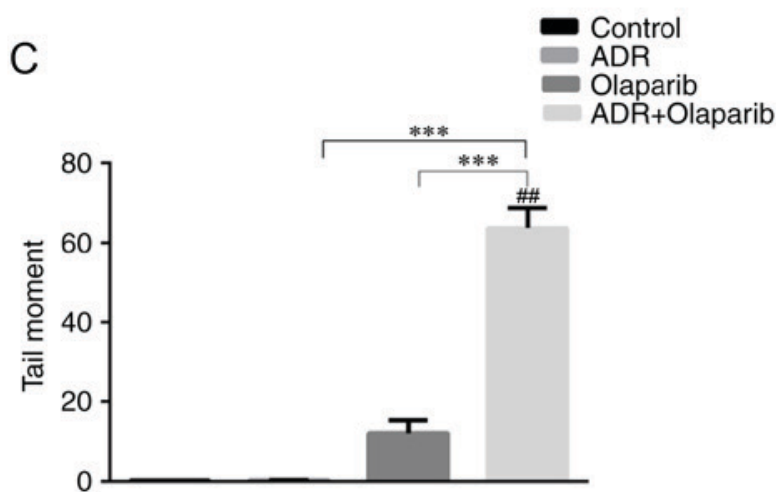

Figure 3. Comet assay detecting DNA damage in K562/ADR cells. (A) Alkaline comet assay. (B) Tail DNA percentage of cells and (C) Tail moment percentage of DNA damaged cells. Data are presented as the mean \pm standard deviation of three independent experiments. ${ }^{* * *} \mathrm{P}<0.001$, as indicated; ${ }^{\# \#} \mathrm{P}<0.01$ and

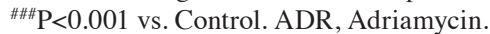

percentage of cells at the $\mathrm{G} 2 / \mathrm{M}$ phase were $38.23 \pm 0.86$ for the control cells, $41.81 \pm 1.94$ for the $2 \mu$ mol ADR-treated K562/ADR cells, $41.97 \pm 1.86$ for the $5 \mu$ mol Olaparib-treated K562/ADR cells and $50.93 \pm 1.53$ for the ADR+Olaparib-treated K562/ADR cells (Fig. 2E and F). K562/ADR cells treated with ADR+Olaparib had a greater number of $\mathrm{G}_{2} / \mathrm{M}$-phase cells than the cells treated with ADR alone, Olaparib alone or the untreated control cells $(\mathrm{P}<0.005, \mathrm{P}<0.01$ and $\mathrm{P}<0.005$, respectively). Cyclin $\mathrm{B} 1$ was markedly downregulated when the K562/ADR cells were treated with ADR+Olaparib (Fig. 2G). Cyclin B1 is the regulatory subunit of Cyclin-dependent kinase 1 , and a reduction in the expression of cyclin $\mathrm{B} 1$ can arrest cells in the G2/M phase of the cell cycle, triggering cell death (19). These results indicate that re-sensitization of ADR resistant leukemia cells may be partly mediated by cell cycle arrest at the G2/M phase (Fig. 2E and F).

Combination of Olaparib and ADR-induced DNA damage. The alkaline comet assay was conducted to investigate the genotoxic potential of DNA damage. Olaparib enhanced DNA damage in ADR treated cells as shown by the prevalence of distinct comet tails (Fig. 3A). The addition of Olaparib enhanced the average tail DNA by $\sim 15$-fold when compared with the control group $(\mathrm{P}<0.001$; Fig. 3B). In addition, the tail moment was enhanced by $\sim 150$-fold $\mathrm{P}<0.01$; Fig. 3C).

Olaparib and ADR induce apoptosis by altering the expression of PARPI, cleaved PARPI, caspase 3, cleaved caspase 3 and $\gamma$-H2AX in K562/ADR cells. The expression of $\gamma$-H2AX was significantly increased in cells treated with Olaparib alone compared with the control cells (Fig. 4). In addition, it was revealed that PARP1 was significantly downregulated and cleaved-PARP, caspase 3 and cleaved caspase 3 were markedly upregulated in cells following Olaparib+ADR treatment, compared with the control group (Fig. 4C and D).

Exposure of mononuclear cells from patients with leukemia, to ADR+Olaparib activates the DNA-damage response and apoptosis. To determine the potential clinical significance of the aforementioned cell line studies, mononuclear cells were isolated from the bone marrow of patients with chemoresistant leukemia 


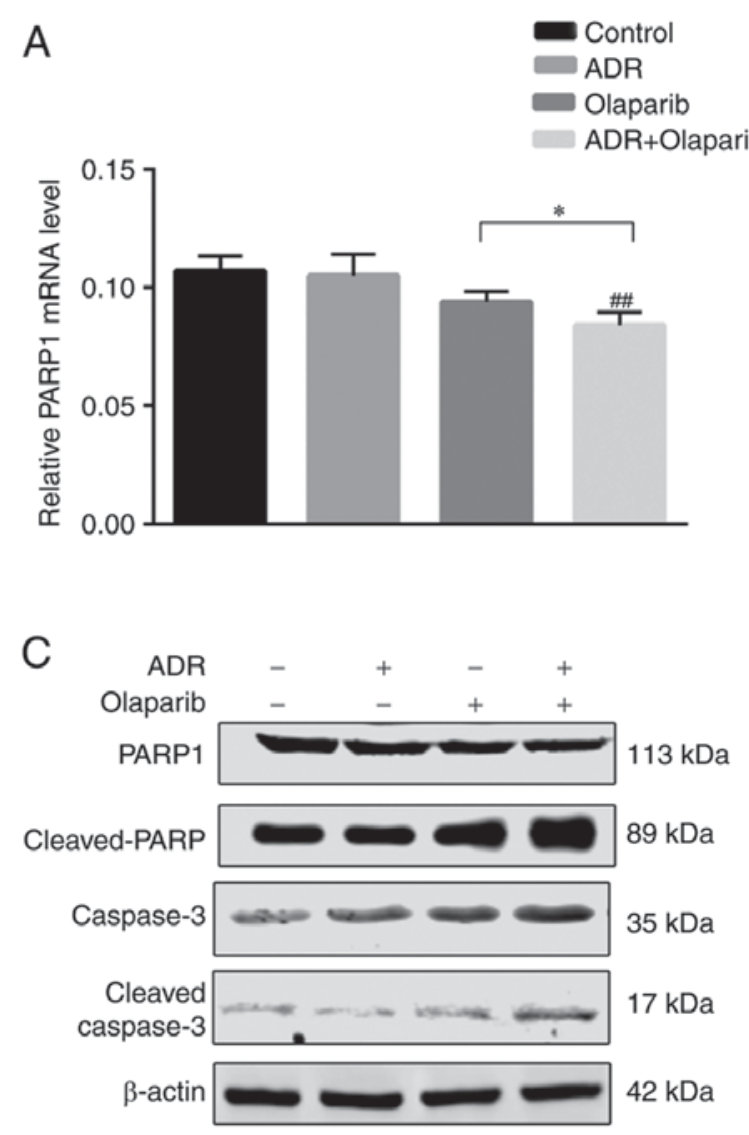

B
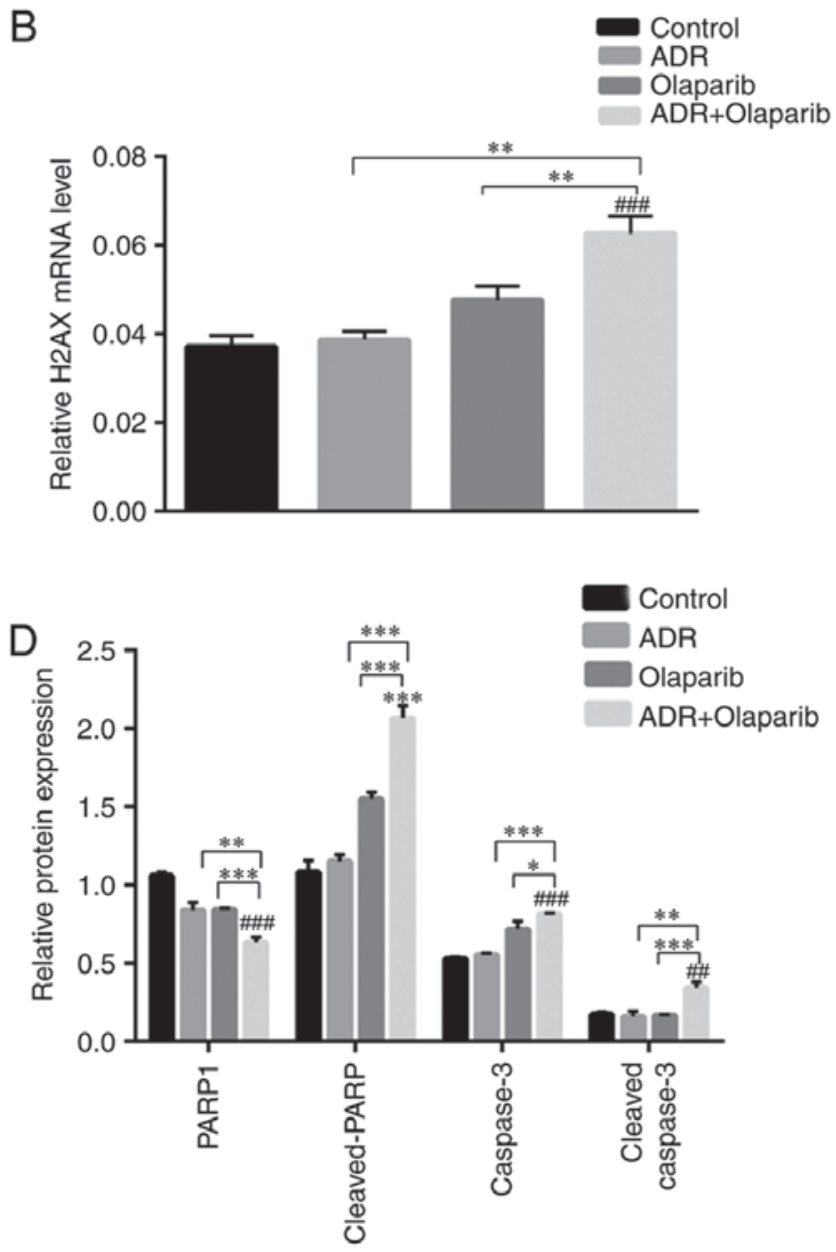

$\mathrm{E}$

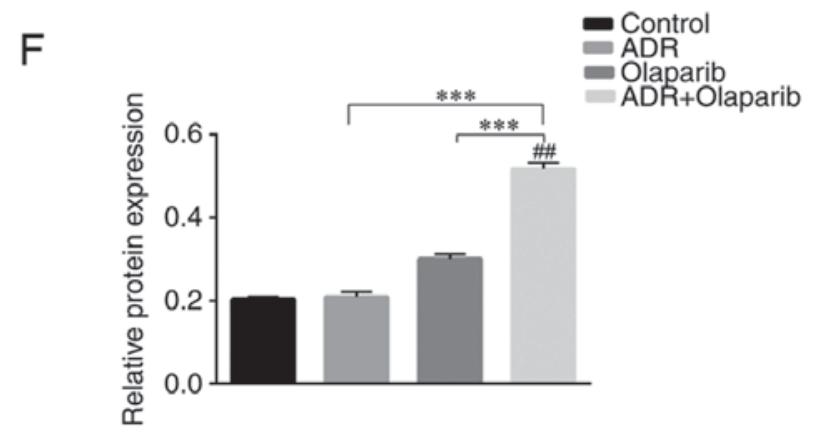

Figure 4. ADR+Olaparib induces apoptosis by altering the protein expression of $\gamma$-H2AX, PARP1, cleaved-PARP, caspase 3 and cleaved-caspase 3 in K562/ADR cells. (A) mRNA expression of PARP1 and (B) H2AX. (C) Western blotting and (D) statistical analysis of PARP1, cleaved-PARP, Caspase 3 and cleaved-Caspase 3 normalized to $\beta$-actin. (E) Western blotting and (F) statistical analysis of $\gamma$-H2AX normalized to $\beta$-actin. Data are presented as the mean \pm standard deviation of three independent experiments. ${ }^{*} \mathrm{P}<0.05,{ }^{* *} \mathrm{P}<0.01$ and ${ }^{* * * *} \mathrm{P}<0.001$, as indicated; ${ }^{\# \#} \mathrm{P}<0.01$ and ${ }^{\# \# \#} \mathrm{P}<0.001$ vs. Control. ADR, Adriamycin; H2AX, H2A histone family member X; PARP, poly (adenosine diphosphate-ribose) polymerase.

(their clinic pathological features are summarized in Table I). These cells were exposed to ADR, to test the degree of ADR resistance (Fig. 5A), as well as individual drugs or a combination of the two. Increased levels of $\gamma$-H2AX were observed in cells from the three leukemia patients exposed to ADR+Olaparib, which indicated that the combined treatment activated a DNA damage response. Cleaved PARP, caspase 3 and cleaved caspase 3 were markedly upregulated in cells exposed to ADR+Olaparib treatment, which indicated that apoptosis was activated (Fig. 5B). These results revealed that there was drug synergism in cells derived from patients with leukemia, involving mechanisms analogous to those observed in the cultured cell lines.

\section{Discussion}

ADR is a time- and dose-dependent antineoplastic agent, which induces DNA damage in leukemia cells via topoisomerase II (20). However, of leukemia cell resistance to ADR reduces DNA damage through the FA/BRCA signaling pathway in DNA inter-strand crosslink repair (21). In recent years, investigators have performed numerous studies using PARP1 inhibitors (13), curcumin (22) and arsenic (23) to reverse multidrug resistance via the FA/BRCA signaling pathway in tumor cells. These previous studies have provided a strong rationale for the development of PARP inhibitors for the treatment of ADR resistant leukemia. 


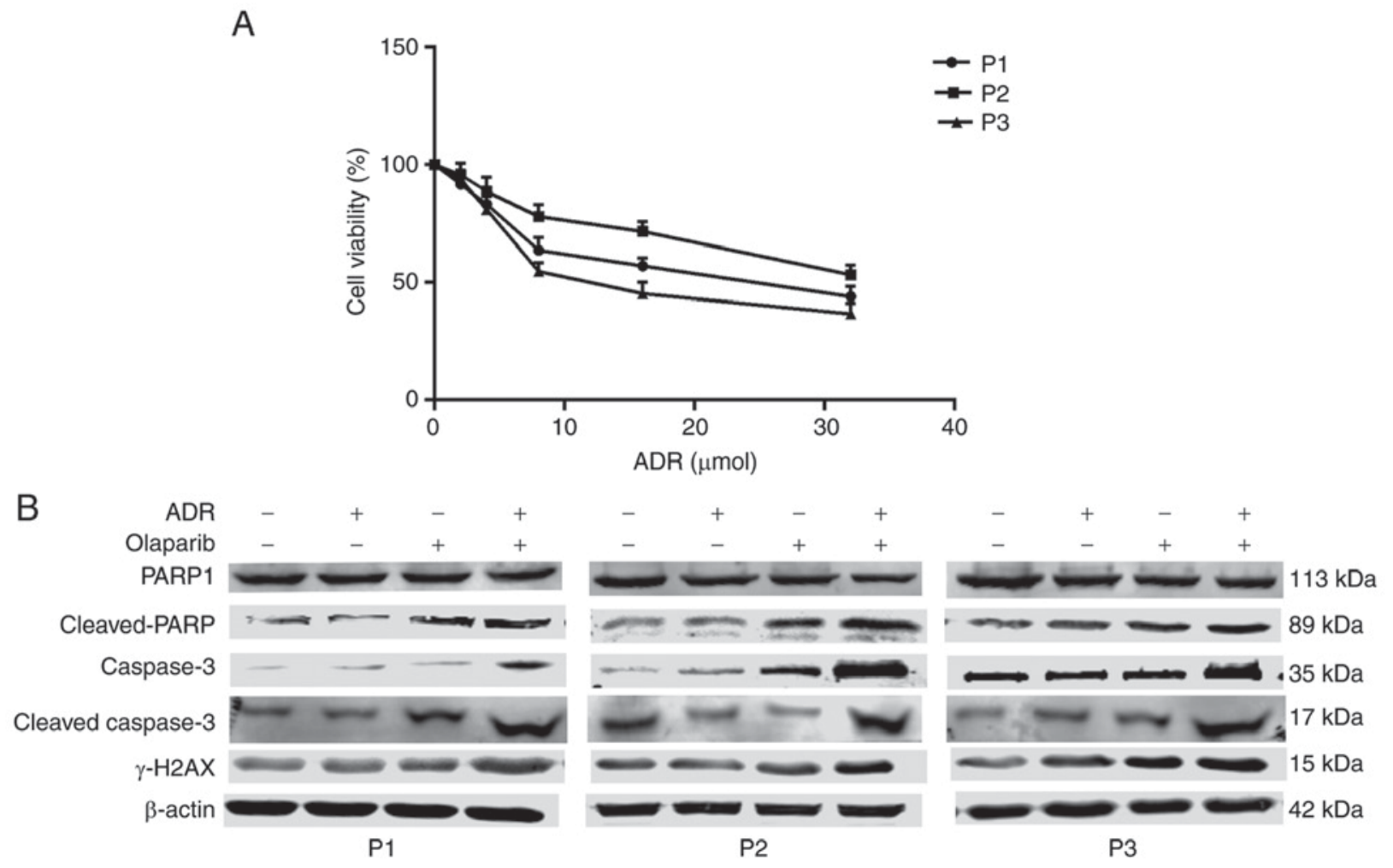

Figure 5. Effect of patient cell sample exposure to drugs on biomarkers of apoptosis and DNA-damage. (A) Cells were exposed to $0,2,4,8,16$ and $32 \mu$ mol/1 ADR for 3 days, and Cell Counting kit- 8 assays were subsequently performed to detect cell viability. Results are all presented as the mean \pm standard deviation of three separate experiments. (B) Cells were exposed to ADR and Olaparib, alone or combined, or the corresponding control for 3 days. Total cell extracts were analyzed by western blotting. ADR, Adriamycin; H2AX, H2A histone family member X; PARP, poly (adenosine diphosphate-ribose) polymerase; P, patient.

K562/ADR cells are multidrug-resistant cells, that acquired resistance by exposing K562 cells to step-wise increased concentrations of ADR. K562/ADR cells are resistant to ADR, mitoxantrone, homoharringtonine, rubidomycin and etoposide (24). K562/ADR cells appear to have sophisticated cross drug-resistance to all of these anti-cancer drugs, which have different structures and functions to one another. The experiments performed in the present study demonstrated that the $\mathrm{IC}_{50}$ of K562/ADR cells was 26.34-60.7 fold greater when compared with K562 cells, which verified that K562/ADR cells were highly resistant to ADR-induced proliferation inhibition and apoptosis.

The effect of Olaparib on the viability of K562/ADR cells was investigated by CCK-8 assays. Olaparib alone did not exhibit a cytotoxic effect on K562/ADR cells at doses up to $5 \mu \mathrm{M}$. The concentrations of Olaparib selected for use within the present study were below the peak concentration of Olaparib $(24 \mu \mathrm{M})$ that has been used in clinical trials (25). The concentrations used in vitro can also be achieved in vivo. The ADR doses used in vitro were dependent on the survival of the K562 and K562/ADR cells. According to the results of previous experiments by the authors, pre-treatment with ADR at $2 \mu \mathrm{M}$ consistently enhanced toxicity in K562 cell lines but not in K562/ADR cell lines (11). Therefore, $2 \mu \mathrm{M}$ ADR and $5 \mu \mathrm{M}$ Olaparib were selected for use in further experiments. Olaparib+ADR was capable of promoting ADR-mediated apoptosis in K562/ADR cells.

Several previous studies have reported that PARP1 inhibitors can exert synergistic inhibitory effects in tumors with various conventional chemotherapeutic agents, including doxorubicin (26), temozolomide (7) and oxaliplatin (27). The results of the present study demonstrated that treatment with Olaparib+ADR produced synergistic effects and revealed a significant increase in the sensitivity of ADR against K562/ADR cells. Cell cycle arrest at any phase will inhibit cell proliferation (28). The results revealed a synergistic effect in the treatment combination of ADR and Olaparib; combined treatment induced $\mathrm{G} 2 / \mathrm{M}$ cell cycle arrest. In addition, the protein expression of Cyclin B1 was downregulated; the inhibition of cyclin B1 could lead to cell cycle arrest in the G2/M phase (29). In conclusion, these results suggested that the combined treatment of ADR and Olaparib may be more effective than monotherapy in treating ADR resistant leukemia.

Histone H2AX serves a critical role in the regulation of DNA damage. H2AX phosphorylation is involved in DNA damage, as well as apoptosis in chronic myelogenous leukemia cells induced by imatinib (30). Olaparib+ADR induced more DNA damage than Olaparib alone in the present study. Olaparib may increase DNA damage induced by ADR by inhibiting DNA damage repair.

To investigate the mechanism of PARP inhibitor re-sensitization in ADR resistant leukemia, the effect of Olaparib on apoptosis-associated proteins, such as cleaved caspase-3, caspase-3 (31), cleaved PARP (32) and PARP1 (33) was investigated. It was revealed that apoptosis induced the upregulation of caspase-3, cleaved caspase-3 and cleaved PARP protein expression, and downregulated PARP1 expression. Caspase-3 is responsible for cleaving specific cellular proteins 
during apoptosis (34). Cell death is accompanied by PARP cleavage, a caspase- 3 substrate (35). Caspase- 3 is the most active effector caspase in the intrinsic and extrinsic pathways where it is processed and activated by caspase- 9 and caspase-8, respectively (36). A high level of caspase-3 activation and cleavage processing was observed in the present study following ADR and Olaparib treatment of drug resistant leukemia cells. PARP1 has a molecular weight of $113 \mathrm{kDa}$ and is located in the nucleus (37). Following treatment with Olaparib+ADR, caspase-3 was activated and PARP1 was cleaved into its $89 \mathrm{kDa}$ (cleaved PARP) and $24 \mathrm{kDa}$ forms, therefore the level of full-length PARP1 (113 kDa) was significantly reduced. $\mathrm{Xu}$ et al (33) reported that caspase 3 activation resulted in the cleavage of PARP1 and increased apoptosis, which is consistent with the results observed in the present study. The results demonstrated drug synergism between the cells derived from patients with chemoresistant leukemia and the cultured cell lines, through analogous mechanisms. Therefore, PARP inhibitor re-sensitization of ADR resistant leukemia may be associated with the PARP1-mediated signaling pathway of caspase-dependent apoptosis. However, the apoptotic molecular mechanism of Olaparib requires further investigation.

In conclusion, the present study provides evidence of a number of associated mechanisms, that combine to generate DNA damage and apoptosis in leukemia cell lines and patient-derived samples. The present study had several limitations, such as the lack of clinical samples, as well as only one cell line demonstrating synergistic interactions between Olaparib and ADR in ADR-resistant leukemia cells. Besides ideally $\gamma-\mathrm{H} 2 \mathrm{AX}$ should be normalized against the total level of $\mathrm{H} 2 \mathrm{AX}$, however, the remaining protein of the present drug-resistant leukemia samples was not enough to complete the H2AX western blot analysis. However, the results can contribute to the design of clinical trials, which seek to evaluate the efficacy of these drug combinations as components of intensified induction therapy, or as a part of optimized pre-transplant conditioning regimens for patients with ADR-resistant leukemia.

\section{Acknowledgements}

Not applicable.

\section{Funding}

The present study was supported by the National Natural Science Foundation of China (grant no. 81570155), Hunan Provincial Health Committee project (grant no. B2015-06), Project Fund for the Project of the Hunan Development and Reform Commission (grant no. 42) and Health Department of Hunan Province (grant no. B2014-035).

\section{Availability of data and materials}

All data generated or analyzed during this study are included in this published article.

\section{Authors' contributions}

CY conceived and designed the experiments. JW wrote the paper and SX revised it critically. JW, QL, WW and MY performed the experiments. LH, SX, YO and GX performed data analysis. WW and YO collected the patient's samples. SX, LH and GX supervised the research group. All authors read and approved the manuscript.

\section{Ethics approval and consent to participate}

The present study was approved by Central South University and written informed consent was obtained from all patients.

\section{Patient consent for publication}

Not applicable.

\section{Competing interests}

The authors declare that they have no competing interests.

\section{References}

1. Zhang X, Ai Z, Chen J, Yi J, Liu Z, Zhao H and Wei $\mathrm{H}$ : Glycometabolic adaptation mediates the insensitivity of drug-resistant K562/ADM leukaemia cells to adriamycin via the AKT-mTOR/c-Myc signalling pathway. Mol Med Rep 15: 1869-1876, 2017.

2. Tabe Y, Konopleva M, Contractor R, Munsell M, Schober WD, Jin L, Tsutsumi-Ishii Y, Nagaoka I, Igari J and Andreeff M: Up-regulation of MDR1 and induction of doxorubicin resistance by histone deacetylase inhibitor depsipeptide (FK228) and ATRA in acute promyelocytic leukemia cells. Blood 107: 1546-1554, 2006

3. Vinod BS, Maliekal TT and Anto RJ: Phytochemicals as chemosensitizers: From molecular mechanism to clinical significance. Antioxid Redox Signal 18: 1307-1348, 2013.

4. Tomicic MT and Kaina B: Topoisomerase degradation, DSB repair, 553 and IAPs in cancer cell resistance to camptothecin-like topoisomerase I inhibitors. Biochim Biophys Acta 1835: 11-27, 2013.

5. Wang YQ, Wang PY, Wang YT, Yang GF, Zhang A and Miao ZH: An Update on Poly(ADP-ribose)polymerase-1 (PARP-1) Inhibitors: Opportunities and challenges in cancer therapy. J Med Chem 59: 9575-9598, 2016.

6. Neri P, Ren L, Gratton K, Stebner E, Johnson J, Klimowicz A, Duggan P, Tassone P, Mansoor A, Stewart DA, et al: Bortezomib-induced 'BRCAness' sensitizes multiple myeloma cells to PARP inhibitors. Blood 118: 6368-6379, 2011.

7. Gill SJ, Travers J, Pshenichnaya I, Kogera FA, Barthorpe S, Mironenko T, Richardson L, Benes CH, Stratton MR, McDermott U, et al: Combinations of PARP inhibitors with temozolomide drive PARP1 trapping and apoptosis in ewing's sarcoma. PloS one 10: e0140988, 2015.

8. Kim G, Ison G, McKee AE, Zhang H, Tang S, Gwise T, Sridhara R, Lee E, Tzou A, Philip R, et al: FDA approval summary: Olaparib monotherapy in patients with deleterious germline BRCA-mutated advanced ovarian cancer treated with three or more lines of chemotherapy. Clin Cancer Res 21: 4257-4261, 2015.

9. Mateo J, Carreira S, Sandhu S, Miranda S, Mossop H, Perez-Lopez R, Nava Rodrigues D, Robinson D, Omlin A, Tunariu N, et al: DNA-repair defects and olaparib in metastatic prostate cancer. N Engl J Med 373: 1697-1708, 2015.

10. Helleday T: PARP inhibitor receives FDA breakthrough therapy designation in castration resistant prostate cancer: Beyond germline BRCA mutations. Ann Oncol 27: 755-757, 2016.

11. Yao C, Du W, Chen H, Xiao S, Huang L and Chen FP: Involvement of fanconi anemia genes FANCD2 and FANCF in the molecular basis of drug resistance in leukemia. Mol Med Rep 11: 4605-4610, 2015.

12. Mouw KW and D'Andrea AD: Crosstalk between the nucleotide excision repair and Fanconi anemia/BRCA pathways. DNA Repair (Amst) 19: 130-134, 2014 
13. Xiong T, Wei H, Chen X and Xiao H: PJ34, a poly(ADP-ribose) polymerase (PARP) inhibitor, reverses melphalan-resistance and inhibits repair of DNA double-strand breaks by targeting the FA/BRCA pathway in multidrug resistant multiple myeloma cell line RPMI8226/R. Int J Oncol 46: 223-232, 2015.

14. D'Andrea AD: Susceptibility pathways in fanconi's anemia and breast cancer. N Engl J Med 362: 1909-1919, 2010.

15. McCabe N, Turner NC, Lord CJ, Kluzek K, Bialkowska A, Swift S, Giavara S, O'Connor MJ, Tutt AN, Zdzienicka MZ, et al: Deficiency in the repair of DNA damage by homologous recombination and sensitivity to poly(ADP-ribose) polymerase inhibition. Cancer Res 66: 8109-8115, 2006.

16. Pacher P, Liaudet L, Bai P, Virag L, Mabley JG, Haskó G and Szabó C: Activation of poly(ADP-ribose) polymerase contributes to development of doxorubicin-induced heart failure. J Pharmacol Exp Ther 300: 862-867, 2002.

17. Livak KJ and Schmittgen TD: Analysis of relative gene expression data using real-time quantitative PCR and the 2(-Delta Delta C(T)) method. Methods 25: 402-408, 2001

18. Xia B, Tian C, Guo S, Zhang L, Zhao D, Qu F, Zhao W, Wang Y, $\mathrm{Wu} \mathrm{X}, \mathrm{Da} \mathrm{W}$, et al: c-Myc plays part in drug resistance mediated by bone marrow stromal cells in acute myeloid leukemia. Leuk Res 39: 92-99, 2015

19. Tang L, Zhang Y, Pan H, Luo Q, Zhu XM, Dong MY, Leung PC, Sheng JZ and Huang HF: Involvement of cyclin B1 in progesterone-mediated cell growth inhibition, $\mathrm{G} 2 / \mathrm{M}$ cell cycle arrest, and apoptosis in human endometrial cell. Reprod Bio Endocrinol 7: 144, 2009.

20. Menear KA, Adcock C, Boulter R, Cockcroft XL, Copsey L, Cranston A, Dillon KJ, Drzewiecki J, Garman S, Gomez S, et al: 4-[3-(4-cyclopropanecarbonylpiperazine-1-carbonyl)-4-fluoroben zyl]-2H-phthalazin-1-one: A novel bioavailable inhibitor of poly(ADP-ribose) polymerase-1. J Med Chem 51: 6581-6591, 2008.

21. Yao C, Du W, Chen H, Xiao S, Huang L and Chen F: The Fanconi anemia/BRCA pathway is involved in DNA interstrand cross-link repair of adriamycin-resistant leukemia cells. Leuk Lymphoma 56: 755-762, 2015.

22. Chen P, Li J, Jiang HG, Lan T and Chen YC: Curcumin reverses cisplatin resistance in cisplatin-resistant lung caner cells by inhibiting FA/BRCA pathway. Tumour Biol 36: 3591-3599, 2015.

23. Peremarti J, Ramos F, Marcos R and Hernandez A: Arsenic exposure disrupts the normal function of the FA/BRCA repair pathway. Toxicol Sci 142: 93-104, 2014

24. Li GY, Liu JZ, Zhang B, Wang LX, Wang CB and Chen SG: Cyclosporine diminishes multidrug resistance in K562/ADM cells and improves complete remission in patients with acute myeloid leukemia. Biomed Pharmacother 63: 566-570, 2009.

25. Fong PC, Boss DS, Yap TA, Tutt A, Wu P, Mergui-Roelvink M, Mortimer P, Swaisland H, Lau A, O'Connor MJ, et al: Inhibition of poly(ADP-ribose) polymerase in tumors from BRCA mutation carriers. N Engl J Med 361: 123-134, 2009.
26. Mariano G, Ricciardi MR, Trisciuoglio D, Zampieri M, Ciccarone F, Guastafierro T, Calabrese R, Valentini E, Tafuri A, Del Bufalo D, et al: PARP inhibitor ABT-888 affects response of MDA-MB-231 cells to doxorubicin treatment, targeting snail expression. Oncotarget 6: 15008-15021, 2015.

27. Xu K, Chen Z, Cui Y, Qin C, He Y and Song X: Combined olaparib and oxaliplatin inhibits tumor proliferation and induces $\mathrm{G} 2 / \mathrm{M}$ arrest and gamma-H2AX foci formation in colorectal cancer. OncoTargets Ther 8: 3047-3054, 2015.

28. Ujiki MB, Ding XZ, Salabat MR, Bentrem DJ, Golkar L, Milam B, Talamonti MS, Bell RH Jr, Iwamura T and Adrian TE: Apigenin inhibits pancreatic cancer cell proliferation through G2/M cell cycle arrest. Mol Cancer 5: 76, 2006.

29. Yadav N, Kumar P, Chhikara A and Chopra M: Development of 1,3,4-oxadiazole thione based novel anticancer agents: Design, synthesis and in-vitro studies. Biomed Pharmacother 95: 721-730, 2017.

30. Dong Y, Xiong M, Duan L, Liu Z, Niu T, Luo Y, Wu X, Xu C and $\mathrm{Lu}$ C: H2AX phosphorylation regulated by p38 is involved in bim expression and apoptosis in chronic myelogenous leukemia cells induced by imatinib. Apoptosis 19: 1281-1292, 2014.

31. Liu B, Jian Z, Li Q, Li K, Wang Z, Liu L, Tang L, Yi X, Wang H, $\mathrm{LiC}$ and Gao T: Baicalein protects human melanocytes from $\mathrm{H}(2)$ $\mathrm{O}(2)$-induced apoptosis via inhibiting mitochondria-dependent caspase activation and the p38 MAPK pathway. Free Radic Biol Med 53: 183-193, 2012.

32. D'Amours D, Desnoyers S, D'Silva I and Poirier GG: Poly(ADP-ribosyl)ation reactions in the regulation of nuclear functions. Biochem J 342: 249-268, 1999.

33. Xu P, Cai X, Zhang W, Li Y, Qiu P, Lu D and He X: Flavonoids of rosa roxburghii tratt exhibit radioprotection and anti-apoptosis properties via the $\mathrm{Bcl}-2(\mathrm{Ca}(2+)) /$ Caspase-3/PARP-1 pathway. Apoptosis 21: 1125-1143, 2016.

34. Cohen GM: Caspases: The executioners of apoptosis. Biochem J 326: 1-16, 1997.

35. Nicholson DW and Thornberry NA: Caspases: Killer proteases. Trends Biochem Sci 22: 299-306, 1997.

36. Nicolini F, Burmistrova O, Marrero MT, Torres F, Hernández C, Quintana J and Estévez F: Induction of G2/M phase arrest and apoptosis by the flavonoid tamarixetin on human leukemia cells. Mol Carcinog 53: 939-950, 2014.

37. Uchida K and Miwa M: Poly(ADP-ribose) polymerase: Structural conservation among different classes of animals and its implications. Mol Cell Biochem 138: 25-32, 1994.

This work is licensed under a Creative Commons Attribution-NonCommercial-NoDerivatives 4.0 International (CC BY-NC-ND 4.0) License. 